\title{
The Impact of School Bullying On Students' Academic Achievement from Teachers Point of View
}

\author{
Hana Khaled Al-Raqqad ${ }^{1}$, Eman Saeed Al-Bourini ${ }^{1}$, Fatima Mohammad Al Talahin ${ }^{2} \&$ Raghda Michael Elias \\ Aranki $^{3}$ \\ ${ }^{1}$ Princess Alia University College, Al Balqa Applied University, Jordan \\ ${ }^{2}$ The World Islamic Sciences \& Education University, Jordan \\ ${ }^{3}$ Faculty of Engineering Technology, Al Balqa Applied University, Jordan \\ Correspondence: Hana Khaled Al-Raqqad, Princess Alia University College, Al Balqa Applied University, \\ Jordan.
}

Received: December 16, 2016

Accepted: January 31, $2017 \quad$ Online Published: May 29, 2017

doi:10.5539/ies.v10n6p44

URL: https://doi.org/10.5539/ies.v10n6p44

\begin{abstract}
The study aimed to investigate school bullying impact on students' academic achievement from teachers' perspective in Jordanian schools. The study used a descriptive analytical methodology. The research sample consisted of all schools' teachers in Amman West Area (in Jordan). The sample size consisted of 200 teachers selected from different schools from Amman West area in Jordan. A self-administrated questionnaire was designed according to research objectives and hypotheses and distributed over research sample subjects. All distributed questionnaire were collected. They were, coded and analyzed by using SPSS version 18. The research results indicated that school bullying exists in all schools regardless if they are governmental or private ones. The study also concluded that school bullying affect student's academic achievement either victims or the bullies.
\end{abstract}

Keywords: school bullying, academic achievement, teachers

\section{Introduction}

Bullying exists in all communities since long time. Bullying exists either in developed or developing societies. Bullying starts in early age. Child starts to build an initial concept of bullying. Then, it starts increasing and continues until it reaches its peak in the basic phase stage $(4,5$, and 6$)$. It continues in higher basic stage, and then started to decline at secondary level (Dickerson, 2005). Bullying is considered a common form of violence in schools. Various studies indicated that bullying makes schools to be unsafe places for schools' students and it contributes in the belief that some schools are become not safe anymore (Maliki et al., 2009).

Shahria et al. (2015) reported that bullying is deemed as a serious problem in academic settings in all parts of the world. They found that bullying has negative impact on academic performance. Females were more affected than males by bullying.

Bullying constitute a complex problem in school kids lives. It is a problem that affects all students, either bullies or victims, and those who attended interpersonal violence. Bullying may involve many sections verbal, physical assaults, threats, jokes or language, and criticizing. All of such factors affect individually, or collectively, and contributes in child's bullying. It is well known that bullying is difficult to eliminate or to stop it in schools because it is used by students. Alison (2016) stated that bullying is considered as global problem that affect emotional, social, and physical wellbeing of school-age children worldwide

Shafqat (2015, p. 45) argued that bullying in schools occurs in any place either in school building or around school building and may occur in bathrooms, school buses and during waiting for school buses, and in classes which may require group work or after school activities. School bullying is a widespread issue that affects school students in many parts of their lives such as; psychologically, educationally and professionally. Sekol and Farrington (2016) found that bullies, compared to non-bullies have been bullied before,

Bullying at school affects academic achievement since bullied children feel fear and weak and in the same time it affects students' personality traits and self-confidence. Therefore such situation makes bullied students unable to follow or to pay attention for their study well and even they might do not like to go to school. Moreover they miss opportunities to participate with their colloquies or even enjoy school activities.. Many researchers found 
that there is a strong relationship between bullying academic achievement,. Students lose concentration when they are attending their classes.

\subsection{Statement of Problem}

Bullying is a problem that affects all students, either the person the bully, the victims, and those who witnesses. Bullying may include verbal, physical assaults, threats, jokes or language, mockery and criticizing, insulting behavior and facial expressions. All of such factors work either individually, or collectively, for contributing in students' likelihood of bullying.

It is well known that bullying is difficult to eliminate or to stop it in schools because it is used by students. Bullying at school has various impact, among such impact is the academic achievement. Therefore the research problem is to determine the impact of school bullying on students' academic achievement from teachers point of view.

\subsection{Study Significance}

The research importance stems from the importance of the topic it deals with, which is considered very important for many parties. Moreover it will enable those concerned know how to deal with the problem of bullying and its obvious consequences on school students achievement. It also enables the victims to know how to avoid being bullied.

\subsection{The Study Purpose}

The study aimed to achieve the following objectives:

1) To specify the impact of bullying in schools in general

2) To find out the impact of bullying in schools on students' academic achievement

\subsection{Definition of Terms}

Bullying: Bullying is defined as "repeated acts of unprovoked aggression that are damaging psychologically or physically for the victim, and where the strength of the aggressor/s and the victim is unequal" (Jankauskiene et al., 2008, p. 46). Bullying is a form of aggression in which there is no imbalance of power between the bully and the victim that occurs mostly in peer group context (Mishna, 2003). Bullying is one of the most evident problems that children face in education system; in addition, it is one of the most important health risks (Raskauskas \& Modell, 2011, p. 64). Bullying is perceived as serious problem in schools in these days (Rose \& Monda-Amaya, 2011, p. 4). Educators understand bullring's dynamics and consequences in addition to what they can do to support students in such situations (Allen, 2010). Bauman (2006) indicated that bullying phenomenon has three components: as follows: first, there must be an intention to harm; second, it is necessary that it happens many times; and finally, it needs to be no balance power between perpetrator and the victim.

School bullying is defined as a form of violence that harms others and it occurs at school or during various activities when a student or group of students uses their strength in hurting other individuals or other groups. The basis of bully's strength is either physical strength or their age or financial situation, or social level or technological skills (Quiroz et al., 2006). School bullying is considered as "aggressive behavior which mostly usually contains no equivalent power between the bully and the victim, and occurs many times over the time". There are many forms of bullying such as physical abuse, verbal abuse and threats of non-verbal communication. Bullying also includes the use of modern communication means for sending various messages of confusing and threatening.

Bullying is referred to frequent aggressive behaviour made by one bully or more bullies. Bullying also in occurred when a student is teased frequently in a way student does not like (Omoteso, 2010). Bullying is deemed as common increasing problem in every society and schools. Bullying occurs in any time and it has negative impacts mainly on students' academic, emotional and social development during school period (Kartal \& Asude, 2009).

Bullying in schools has many and different causes, in this regard Omoteso (2010) indicated that characteristics of personality and typical reaction patterns, all together combined with physical strength or weakness level in boys, can help in explaining bullying problems development in individual students. In addition to environment impacts, such as teachers' attitudes, behaviours and supervisory routines which play an important role in determining such problems in school? In addition parents have great impact in this concern so if they use aggression as a way of meeting their needs, or use harsh or aggressive methods of discipline shall have children who engage in aggression or bullying Omoteso (2010) 
Bullying includes physical and verbal violence includes power and control and the desire to control the destiny of others from peers and colleagues, this behavior exists among students in all stages of public education and can lead to violence comprehensive sense. Aggressive behavior is offensive is not justified and the damage to the same people or property or the environment and nature may be aggression verbally or in practice

Bullying Forms:

There are several forms of bullying as follows: (Quiroz et al., 2006)

1. Physical bullying: such as hitting, slapping, kicking or forced to do something.

2. Verbal bullying: verbal abuse, insults, cursing, excitement, threats, false rumors, giving names and titles for individual, or giving ethnic label.

3. Sexual bullying: this refers to use dirty words, touch, or threat of doing.

4. Psychological bullying: harassment, threats and intimidation, humiliation and rejection from the group.

5. Bullying in social relations: preventing some individuals from exercising certain activities or reject their friendship or spreading rumors about others.

6. Properties Bullying: taking other people's things and dispose, or destroy.

\section{Review of Related Literature}

Impact of bullying on Academic achievement:

Cythia (2014) analyzed bullying impact on student's performance either in short or long term. She found that there are differences in relationship between bullying level and academic performance depending on student's academic achievement. Nadine (2014) investigated bullying impact on student's ability to academically succeed. Nadine found that bullied students have feel of fear from coming to school because they feel that they are unsafe; therefore they are unable to concentrate which reelect negatively on their academic success. Mundbjerg et al. (2014) analyzed the relationship between bullying in elementary school in Denmark. They found that bullied students have lower academic achievement in $9^{\text {th }}$ grade and bullying impacts are larger if it is more severe. Placidius (2013) found that physical bullying was perceived as a dominant bullying element. Boys prefer to be bullies more than girls. Poor academic performance was as impact of bullying.

Mehta et al. (2013) found that when students feel that bullying is a phenomenon in their school, they feel that they are unsafe which reflected on less engaged in school community. Therefore they have less motivation to do well at school and they do not participate in school activities. Bullying affects student's academic achievement in various ways. Ammermueller (2012) found that being bullied has a significantly negative impact on present and future students' performance in school

Brank et al. (2012) indicated that bullying victims are weak, shy, and anxious. They added that victims' performance is poor in school and seek to avoid attending school classes for the purpose of avoiding victimization. Victimization experiencing can lead to poor academic performance and leading to absenteeism. Skapinakis et al. (2011) found that victims were more likely to report suicidal thoughts than were bullies.

Juvonen, et al. (2011) said that bullying experiences affect victims' academic achievement in both direct and indirect ways. So bullied student by his peers may become worried and afraid of being teased, therefore he may stop participating in class or may has e trouble in concentrating on class work because of fear. They added that students who are often subject to be bullied by their peers during school period have less engagement at school and poor grades. Konishi et al. (2010) confirmed that interpersonal relationships within school environment influence academic achievement.

Roman and Murillo (2011) found that aggression in schools has a negative effect on academic achievement in Latin America. They affirmed that students who have been physically or verbally abused perform less. Marcela and Javier (2011) found that bullying is a serious problem throughout Latin America they indicated that; students who suffer from their peers aggression have lower performance in reading and math than those who do not; and students who are in classrooms with more physical or verbal violence perform are more worse than those in less violent classroom settings. Konishi et al. (2010) found that school bullying affects negatively academic achievement.

Chaux et al. (2009) argued that ten to fifteen percent of adolescents worldwide are bullied two or more times a month. Skrzypiec (2008) found that third of students who had been seriously bullied reported having serious difficulties in concentrating and paying attention in class because of bullying and the fear associated with. Glew 
et al. (2005) reported that bullying prevents concentration and subsequent academic achievement since bullying victims lose interest in learning and experience a drop in academic grades because their attention is distracted from learning. Mishna (2003) indicated that bullying is "a form of aggression in which there is an imbalance of power between the bully and the victim that occurs largely in the context of the peer group".

\section{Design and Methodology}

\subsection{Population and Sampling}

The targeted population consisted of all males and females teachers of (6th and 7th Grades) in Amman West area school (public and private ones). A convenient sample was selected totaling 220 teachers for the two classes from different schools.

\subsection{Study Instrument}

A self-administrated questionnaire was designed according to research objectives and hypothesis. The questionnaire was validated through universities instructors and experts' opinions. After improving the instrument in terms of language, style, format, and content, it was administered on the 200 students.

A Cronbach's Alpha was also used to measure questionnaire internal consistency and reliability. The subjects were asked to indicate their level of agreement corresponding to each item and were rated at five point Likert Scale: strongly disagree $=1$, Disagree $=2$, Neutral $=3$, agree $=4$, strongly agree $=5$.

\subsection{Data Collection and Analysis}

Two data collection methods were used. Books, periodicals, journals, references and the internet were used for collecting the required secondary data while self-administrated questionnaire was used and distributed to the research sample for the purpose of collecting the primary data.

\subsection{Research Validity and Reliability}

University instructors examined the questionnaire, their comments and amendments were taken in consideration. Therefore some items were canceled or added to form the final copy of the questionnaire. The research study used Cronbach alpha to find out the results consistency.. It was found, the questionnaire reliability level was equal to $(0.91)$ which is acceptable.

\section{Results of the Study}

Table 1. Means and Standard deviation of bullying existence in the sample school

\begin{tabular}{|c|c|c|c|c|c|}
\hline No. & Statements & Mean & S. Deviation & Rank & Level \\
\hline 1 & There is a lot of bullying in the school & 4.3000 & .45854 & 1 & High \\
\hline 2 & $\begin{array}{l}\text { Teachers sometimes humiliated you in front of the } \\
\text { class }\end{array}$ & 4.0000 & .44749 & 3 & High \\
\hline 3 & $\begin{array}{l}\text { Teachers sometimes bully students to the point that } \\
\text { affect their academic achievement }\end{array}$ & 3.9000 & .53885 & 5 & High \\
\hline 4 & School witnessed many bullying events every day & 4.2000 & .40025 & 2 & High \\
\hline 5 & Bullying took place in all school facilities & 3.9000 & .30019 & 5 & High \\
\hline 6 & Older students often use school bullying & 3.9000 & .53885 & 5 & High \\
\hline 7 & Lack of teachers intervention encourages bullying & 3.3912 & 1.02322 & 8 & High \\
\hline 8 & $\begin{array}{l}\text { Teachers' bullying discourages student to go to } \\
\text { class }\end{array}$ & 4.0000 & .00000 & 3 & High \\
\hline
\end{tabular}

Table 1 indicated means and standard deviations of sample's subjects. With respect to bullying existence in the school, the means of sample's responses ranged between (3.39-4.30) All responses indicated the subjects agreement was high level. Statement no. 1 "There is a lot of bullying in the school" ranked the first", while statement No. 7 "Lack of teachers intervention encourages bullying" ranked the last. By reviewing the means it seems that bullying exists in the school, which seems logic since every school witnessed bullying every day and no way to avoid it. 
Table 2. Means and standards deviations for sample's responses regarding school bullying impact on victim academic achievement

\begin{tabular}{|c|c|c|c|c|c|}
\hline No. & Statements & Mean & S. Deviation & Rank & Level \\
\hline 9 & Bullying affected negatively students' academic level & 3.2000 & .74880 & 2 & Medium \\
\hline 10 & $\begin{array}{l}\text { Students Exam results were poor because of school } \\
\text { bullying }\end{array}$ & 3.2000 & .74880 & 2 & Medium \\
\hline 11 & $\begin{array}{l}\text { School bullying creates negative environment in the } \\
\text { school }\end{array}$ & 4.0000 & .44749 & 1 & High \\
\hline 12 & Verbal abuse affects students' academic achievement & 3.0000 & 1.00063 & 4 & Medium \\
\hline 13 & Bullying discourages students to attend classroom & 3.0000 & 1.00063 & 4 & Medium \\
\hline 14 & Students suffer only from their peers bullying & 2.3987 & .92375 & 8 & Medium \\
\hline 15 & Have low motivation to learn & 2.5362 & 1.17491 & 7 & Medium \\
\hline 16 & Disinterest in academic performance & 3.0000 & .83718 & 4 & Medium \\
\hline
\end{tabular}

Table 2 indicates the means and the standard deviations of sample's subject. With respect to impact of bullying on victim academic achievement the means of sample's responses ranged between (2.40- 4.00) All subjects responses indicate subjects agreement were of medium and high level. Statement no 1 "School bullying creates negative environment in the school" ranked the first", while statement No. 8 "Students suffer only from their peers bullying" ranked the last. By reviewing the means the sample's responses, it is clear that bullying affects bullied academic achievement since they do not concentrate in the class room and they feel afraid from being bullied and attempt to avoid being in school which negatively avoid their academic achievement.

Table 3. Means and standards deviations for sample's responses regarding school bullying impact on bully's academic achievement

\begin{tabular}{|c|c|c|c|c|c|}
\hline No. & Statements & Mean & S. Deviation & Rank & Level \\
\hline 20 & Dissatisfaction with the academic experience & 3.9875 & .73870 & 2 & High \\
\hline 21 & Disengaged from his school community & 3.9975 & .73870 & 1 & High \\
\hline 17 & Having difficulties to follow school rules & 3.9963 & .85273 & 3 & High \\
\hline 22 & Exhibit, ore negative attitude towards school work & 3.7250 & .74838 & 3 & High \\
\hline 18 & Don't obey school norms & 3.6325 & .88086 & 6 & Medium \\
\hline 19 & Frequently tardy and absent & 3.6425 & .88086 & 5 & Medium \\
\hline
\end{tabular}

Table 3 indicates the means and the standard deviations of sample's subjects. With respect to impact of bullying on bullies academic achievement responses ranged between (3.63-3.99) All subjects responses indicate subjects agreement) were between medium and high level. Statement no. 21 "Disengaged from his school community." ranked the first", while statement No. 18“Don't obey school norms" ranked the last. Although bullying affects bullied academic achievement, but in the same time it also affects bullies academic achievement since it reduce their interest in the school and have no motivation to learn in addition to other factors.

Table 4. First hypothesis test results

\begin{tabular}{lccccc}
\hline Variable & $\mathbf{R}$ & $\left(\mathbf{R}^{2}\right)$ & $\mathbf{B}$ & $(\mathbf{T})$ & Sig \\
\hline Victims academic achievement & .190 & .036 & .350 & 5.461 & 0.000 \\
\hline
\end{tabular}

Table 4 indicated that there is a statically significant impact of school bullying on victims academic achievement since the significance level is $(0.00)$. Table also demonstrates that $\left(\mathrm{R}^{2}\right)=(0.19)$ which indicate that school bullying and interpret (19\%) of the change in victim's academic achievement. The rest $81 \%$ is related to other factors that were not included in the analysis

Therefore null hypothesis is rejected and the alternative is accepted. This means that there is a statistically significant impact at significance $(\alpha \leq 0.05)$ level of school bullying on victims academic achievement from teachers perspective

Second sub-hypothesis testing Results: 
There is no statistically significant impact at significance level $(\alpha \leq 0.05)$ of School bullying on bullies achievement in government and private schools in Jordan from teachers perspectives.

Table 5. Impact of bullying on achievement

\begin{tabular}{lccccc}
\hline Variable & $\mathbf{R}$ & $\left(\mathbf{R}^{2}\right)$ & $\mathbf{B}$ & $(\mathbf{T})$ & Sig \\
\hline Bullies academic achievement & .194 & 0.038 & .487 & 5.589 & 0.000 \\
\hline
\end{tabular}

Table 5 indicated that there is a statically significant impact of school bullying on bullies academic achievement since the significance level is $(0.00)$. Table also demonstrates that $\left(\mathrm{R}^{2}\right)=(0.038)$ which indicate that school bullying interpret (3.8\%) of the change in bullies academic achievement in from schools' teacher perspective

Therefore the null hypothesis is rejected and the alternative is accepted, which means that there is a statistically significant impact at significance $(\alpha \leq 0.05)$ level of school bullying on bullies academic achievement in government and private schools in Jordan from the perspective of schools' teachers.

\subsection{Conclusions and Recommendations}

The research concluded that bullying exists an almost every school either governmental or private one but with different levels. The search found that school bullying affect academic achievement either for the victims who suffer from these phenomena and in the same time it affects the bullies themselves.

The research suggested that teachers and the school management have to take different measures for the purpose of reducing the bullying volume. Moreover teachers should coordinate with bully's students. Teachers and school management have to set some programs for bullies to mitigate the school bullying.

\section{References}

Allen, K. P. (2010). Classroom Management, Bullying, and Teacher Practices. The Professional Educator, 34(1), $1-15$.

Ammermueller, A. (2012). Violence in European schools: A widespread phenomenon that matters for educational production. Labour Economics, 19(6), 908-922. https://doi.org/10.1016/j.labeco.2012.08.010

Bauman, S., \& Del Rio, A. (2006). Pre service teachers' responses to bullying scenarios: Comparing physical, verbal, and relational bullying. Journal of Educational Psychology, 98(1), 219-231. https://doi.org/10.1037/0022-0663.98.1.219

Block, N. (2014). The Impact of Bullying on Academic Success for Students with and without Exceptionalities (Master of Teaching thesis. University of Toronto, Canada).

Boswell, A. M. (2016). School Level Predictors of Bullying Among High School Students (PhD Lexington, Kentucky University of Kentucky).

Brank, E. M., Hoetger, L., \& Hazen, K. P. (2012). Bullying. The Annual Review of Law and Social Science, 8, 213-230. https://doi.org/10.1146/annurev-lawsocsci-102811-173820

Chaux, E., Molano, A., \& Poflrsky, P. (2009). Socio-economic, socio-political and socio-emotional variables explaining school bullying: A country-wide multilevel analysis. Aggressive Behavior, 35, 520-529. https://doi.org/10.1002/ab.20320

Cynthia, V. (2014). The Effects of Bullying on Academic Achievement. Desarro. soc. no. 74, bogotá, segundo semestre, 275-308

Dickerson, D. (2005). Cyberbullies on campus. University of Toledo Law Review, 37 estudiantes y desempeño escolar. Revista Cepal, 104, 37-54.

Glew, G. et al. (2005). Bullying, psychosocial adjustment, and academic performance in elementary school. Archives of Pediatrics \& Adolescent Medicine, 159(11), 1026-1031. https://doi.org/10.1001/archpedi.159.11.1026

Gomez-Ortiz, O., Romera, E. M., \& Ortega-Ruiz, R. (2016). Parenting styles and bullying. The mediating role of parental psychological aggression and physical punishment. Child Abuse \& Neglect, 51, 132-143. https://doi.org/10.1016/j.chiabu.2015.10.025

Hülya, K., \& Asude, B. (2009). Bullying and School Climate from the Aspects of the Students and Teachers. Kurasian Journal of Educational Research, 36, 209-226. 
Husain, S., \& Jan, A. (2015). Bullying in Elementary Schools: Its Causes and Effects on Students. Journal of Education and Practice, 6(19), 43-56.

Jankauskiene, R., Kardelis, K., Sukys, S., \& Kardeliene, L. (2008). Associations between school bullying and psychosocial factors. Social Behavior and Personality, 36(2), 145-162. https://doi.org/10.2224/sbp.2008.36.2.145

Kibriya, S., Xu, Z. P., \& Zhang, Y. (2015). The impact of bullying on educational performance in Ghana: A Bias-reducing Matching Approach elected. Paper prepared for presentation for the 2015 Agricultural \& Applied Economics Association and Western Agricultural Economics Association Annual Meeting, San Francisco.

Konishi, C., Hymel, S., Zumbo, B. D., \& Li, Z. (2010). Do school bullying and student teacher and academic achievement. Canadian Journal of School Psychology, 25(1), 19-39.

Maliki, A. E., Asogwara, C. C., \& Ibu, J. E. (2009). Bullying and its Effects on the Academic Performance of Secondary School Students in Nigeria. J Hum Ecol, 25(3), 209-213.

Mishna, F. (2003). Learning disabilities and bullying. Journal of Learning Disabilities, 36(4), 336-347. https://doi.org/10.1177/00222194030360040501

Mundbjerg, T., Eriksen, L., Nielsen, H. S., \& Simonsen, M. (2014). Bullying in Elementary School. Journal of Human Resources, 49(4), 839-871.

Ndibalema, P. (2013). Perceptions about Bullying Behaviour in Secondary schools in Tanzania: The case of Dodoma Municipality. International Journal of Education and Research, 1(5), 1-16.

Omoteso, B, A. (2010). Bullying behaviour, its adolescent factor and psychological effects among secondary school students in Nigeria. The journal of international social research, 3(10), 498-509.

Quiroz, H. C., Arnette, J. L., \& Stephens, R. D. (2006). Bullying in schools: Discussion activities for school communities. Retrieved from http://www.schoolsafety.us

Raskauskas, J., \& Modell, S. (2011). Modifying anti-bullying programs to include students with disabilities. Teaching Exceptional Children, 44(1), 60-67. https://doi.org/10.1177/004005991104400107

Rose, C. A., Monda-Amaya, L. E., \& Espelage, D. L. (2011). Bully perpetration and victimization in special education: A review of the literature. Remedial and Special Education, 32(2), 114-130. https://doi.org/10.1177/0741932510361247

Sekol, I., \& Farrington, D. P. (2016). Personal characteristics of bullying victims in residential care for youth. Journal of Aggression, Conflict and Peace Research, 8(2), 99-113. https://doi.org/10.1108/JACPR-11-2015-0198

\section{Copyrights}

Copyright for this article is retained by the author(s), with first publication rights granted to the journal.

This is an open-access article distributed under the terms and conditions of the Creative Commons Attribution license (http://creativecommons.org/licenses/by/4.0/). 